\title{
Directional Movement Distribution in the Bitcoin Markets
}

\author{
Beata Szetela ${ }^{1}$, Grzegorz Mentel ${ }^{2}$, Urszula Mentel ${ }^{3}$, Yuriy Bilan ${ }^{4}$
}

${ }^{1,2,3}$ Rzeszow University of Technology

Al. Powstancow Warszawy 12, 35-959 Rzeszow, Poland

E-mail. ${ }^{1}$ beata@prz.edu.pl; ${ }^{2}$ gmentel@prz.edu.pl; ${ }^{3}$ u.mentel@prz.edu.pl

${ }^{4}$ Tomas Bata University in Zlin

5139 Mostni Str., Zlin, 760 01, Czech Republic

E-mail.yuriy_bilan@yahoo.co.uk

cross'ref $^{\text {http://dx.doi.org/10.5755/j01.ee.31.2.25162 }}$

\begin{abstract}
The crypto exchanges operate primarily on the internet, where the speed of information spreading is significant. Therefore, it is expected that there should be no significant differences among the individual exchanges concerning the same asset being traded. Prices should quickly reach comparable values on all stock exchanges, and they should return to equilibrium in a relative time frame. Hence, the investors, while making decisions on the selection of a cryptocurrency market, should be guided primarily by the exchange security considerations, its flexibility, availability of a product offer, and costs of order processing. The work aims to check whether virtual currency exchanges differ from each other in the context of directional movement, both in an upward and downward trend. To achieve the objective of the paper, we used Directional Movement Index, supported by the Directional Indicators, to compare the distribution of the strength of the directional movement across three different cryptocurrency exchanges (Bitstamp, Coinbase, Kraken) within the up and the downward price movement phase. The comparison is made based on the results of the non-parametrical tests such as Wilcoxon test, Hodges Lehmann test, Ansari-Bradley test, and Conover test. The results show that theoretically, the choice of a cryptocurrency exchange in an upward trend will cause no significant difference for an investor and its strategy. However, the choice of a stock exchange in a downward trend may have a substantial impact on the rates of return.
\end{abstract}

Keywords: Volatility; Bitcoin; Directional Movement; DMI; ADX; Distribution.

\section{Introduction}

The economics of the cryptocurrency market is problematic, and, thus still, unexplored. The followers of cryptocurrencies stress many advantages like anonymity, lack of control, independence, versatility, as well as immense implementation potential. Some partisans perceive in cryptocurrencies, especially in bitcoin a successor of a global currency like the US Dollar. The opponents use almost the same arguments against cryptocurrencies. The market for cryptocurrencies is organized in a specific way. There is not one cryptocurrency market or exchange, where all cryptocurrencies are traded, but there are over 200 different active exchanges. Some of them allow to exchange cryptocurrencies to the most popular fiat currencies, and some of them are dedicated to exchange cryptocurrencies to other cryptocurrencies. The cryptocurrency market is not subject to such a restrictive controls and legal restrictions as traditional financial markets, which in combination with traded assets class means that investors are more likely not only to lose their assets due to hacker attacks on crypto exchanges but are also sensitive to negative information about cryptocurrencies and legal attempts to limit their trade ((FSB, 2018)).

Crypto-markets operate primarily on the internet, in a mass medium to which it is easy and almost no-cost access, where the speed of information spreading is significant. Therefore, there should be no significant differences between the individual exchanges in relation to the same asset being traded. Prices should quickly reach comparable level on all stock exchanges and return to equilibrium in a comparable time frame. Therefore, the potential investors and participants of the cryptocurrency markets when making decisions on the selection of exchange should be guided primarily by the exchange security considerations, its flexibility, availability of a product offer and costs of order processing. The verity of exchanges and traded cryptocurrencies, unrestricted information access, high speed of information processing and relative low transaction costs can be a good starting point for meeting the prerequisites of market efficiency and in the future, it may be a fulfillment of the hypothesis of an effective market (EMH). (Fama, 1970) assumed that the current market prices incorporate at any time all available information, which implies, that the future prices cannot be foreseen, based on the past prices, hence the abnormal returns cannot be achieved. Three forms of EMH are being distinguish (Jensen, 1978; Naseer \& Tariq, 2015; Plastun et al., 2019):

1. The weak form: the current prices incorporate all historical data, hence it is impossible to predict the future market development and receive the abnormal returns based on the technical trend analysis.

2. The semi-strong form: the current prices incorporate all historical and public information, such as dividend announcements, public news, political events, therefore the fundamental analysis is inefficient 
3. The strong form: the current prices incorporate complete knowledge about the traded asses including historical, public and private information

There is an extensive amount of papers trying to analyze the EMH from the various perspectives and referring to different markets. The received results are not homogeneous. While analyzing different forms of efficiency, the most authors support the week efficiency form, e.g. (Alexander, 1961a, 1961b; Fama \& Blume, 1966; Granger, 1975; Hawawini, 1984; Fama E. , Efficient Capital Markets II, 1991; Lo, 1997), before the semi-strong form, e.g. (Hadi, 2006; Dhar \& Chhaochharia, 2008; Mackey \& Bacon, 2017). However many authors reported the contradictory or mixed results, e.g. (Hamid et al., 2010) exanimated the Asia Pacific markets and concluded, that the monthly prices don't follow a random walk and arbitrage across this markets is possible. Dahel \& Laabas (1999) claimed that EMH is valid for the Kuweit, but invalid for Bahrain, Saudi Arabia and Oman within the years 19941998. Worthington \& Higgs (2004) compered 20 European countries (16 developed and 4 emerging economies). They concluded, that only five developed countries (Germany, Ireland, Portugal, Sweden, the United Kingdom) follow random walk in the strict sense and other five (France, Finland, Netherlands, Norway, Spain) follow the random walk hypothesis. Among emerging economies only Hungary fulfills the presumption of the week form of efficiency. Joseph et al. (2017) didn't support the semistrong form of EMH based on research conducted over 40 companies listed on the Bahrain Stock Exchange.

In the extensive literature on issues related to virtual currencies, four main trends of interest can be distinguished: considerations of a general nature, e.g., (Rogojanu \& Badea, 2015; Liu et al., 2015; Gandal et al., 2018; Jagwani, 2015; Dwyer, 2015; Urquhart, 2017; Corbet et al., 2018; Garrat \& Wallace, 2018). Technical studies focused mainly on issues related to acquisition (mining), trade and broadly understood security, e.g., (Badev \& Chen, 2014; Ziegeldorf et al., 2018; Biryukov \& Tikhomirov, 2019; Luther \& Olson, 2015; Alshamsi \& Andras, 2019; Szetela et al., 2016). Considerations regarding legal and tax regulations as well as potential and possible solutions that could regulate the functioning of cryptocurrencies in the financial space, e.g. (Plassaras, 2013; Mandjee, 2015; Bryans, 2014; Campbell-Verduyn, 2018). The largest group are studies on the use of quantitative methods, which are predominantly focused on the analysis of volatility, e.g., (Haubo Dyhrberg, 2016a, 2016b), (Kiss et al., 2017; Muharam et al., 2019) applied asymmetric GARCH and concluded that bitcoin bear resemblance to a currency like the US dollar, as well as a commodity like Gold, thus can be useful for heading, and supportive for portfolio management. Salim et al. (2018) came to different conclusions after investigated long-range memory in Bitcoin market volatility using the FIGARCH model. They noticed that the volatility of the seven bitcoin markets is random, thus in their opinion, they can't be used for heading purposes. Bouoiyour \& Selmi (2016) applying Component with multiple threshold-GARCH and Asymmetric-power GARCH models showed that bitcoins' price is sensitive to negative shocks and still exhibits features of immature markets, despite that the volatility is declining compared to the period before 2015. Koutmos
(2018) show using the VAR model that there are linkages between Bitcoin returns and transaction activity. The Technical analysis is rarely used in bitcoin analysis, e.g. Huang et al. (2019) used 132 technical indicators coming from the five different groups (overlap studies indicators, momentum indicators, cycle indicators, volatility indicators, and pattern recognition indicators) to investigate the predictability of future bitcoins price range. Some authors examine trading strategies on cryptocurrencies e.g., (Detzel et al., 2018; Zbikowski, 2016; Feng et al., 2018; Czaplinski \& Nazmutdinova, 2019; Hudson \& Urquhart, 2019).

Researchers while analyzing cryptocurrencies seems to omit the fact, that there are dozens of active cryptocurrency exchanges, which differ in terms of traded assets, volume, scope, fees etc. The multiplicity of exchanges causes different quotation of the same asset among different exchanges, which affects the results of analyzes based on these assets. Only few authors have compared results among different exchanges, e.g. Pieters \& Vivanco (2017) claimed that the bitcoins' price varies among exchanges. Brandvolt et al. (2015) compared investigated 7 crypto-exchanges in the context of price discovery. They have also received not homogeneous results among exchanges.

Not many papers are dedicated to the research on efficiency of cryptocurrency markets, e.g., Brauneis \& Mestel (2018) concluded, that bitcoin is the most efficient cryptocurrency and its efficiency is positively related to its liquidity. Demir et al. (2018) claimed that economic policy uncertainty index has the predictive power on bitcoin, which contradict the EMH. Based on the data between 2013 and 2016 Urquhart (2016) concluded that bitcoin market is inefficient, but it tends to efficiency. Nadarajah \& Chu (2017) and Bariviera (2017) bitcoin doesn't support the EMH. Beside the high volatility which is distinctive for bitcoin and which, according to Shiller (1981), is a denial of the hypothesis of the efficient markets, cryptocurrencies are also characterized by the informed trading (Feng et al., 2018), the price clustering (Urquhart, 2017), and the speculative bubbles (Cheah \& Fry, 2015; Corbet et al., 2017).

In the current literature bitcoins' markets are analyzed in the context of its volatility, security, forecasting ability, but little or even no attention was paid to present bitcoin's variability in the context of technical analysis. This paper contributes to the current research by implying the technical analysis, by using the Directional Movement Index, supported by the Directional Indicators, to compare the distribution of the strength of the directional movement across three different cryptocurrency exchanges (Bitstamp, Coinbase, Kraken) within the up and the downward price movement. The results show whether the choice of the exchange can be valuable in the context of the chosen trading strategy. The potential differences among exchanges can be seen as bitcoins' market inefficiency and space for an arbitrage.

\section{Methodology}

As a basis for our research, we used an Average Directional Movement Index (ADX), which was constructed by Wilder Jr. (1978) and described in a book "New Concepts in Technical Trading Systems". This indicator contains some 
advantages, which we see as desirable for cryptocurrencies. ADX was designed to support commodity trading technically, but it can also be used for financial assets. It was designed to manage market volatility based on a price range. Average Directional Movement Index, together with the two supportive lines, a positive and a negative directional movement line, can be used to detect and measure the strength and a direction of a trend. Its primer application is to decide whether to take a long or short position on trend markets. In our research, we will not discuss possible trading strategies, resulting from the signals produced by the ADX, but we will use it, to detect possible differences in trends magnitude across markets.

Average Directional Movement Index is a complex tool constructed on the basis of other indicators like Directional Movement (DM), Average True Rate (ATR), Directional Indicator (DI), True Directional Movement (TDM). Wilder, in his book described in details steps which are needed to be taken to calculate ADX. First of all, it is necessary to calculate plus and minus Directional Movement (DM) as well as True Range (TR), which are the basis for other indicators, such as plus and minus Directional Indicator, from which ADX results directly. A detailed description of the procedure in calculating ADX is presented below.

TR is understood as the largest value of the difference between either today's high and today's low, or an absolute value of today's high and yesterday's close, or an absolute value of today's low and yesterday's close. Formally a true rate is describes in eq. 1 :

$$
T R_{t}=\max \left\{\begin{array}{c}
\operatorname{high}_{t}-\text { low }_{t} \\
\mid \text { high }_{t}-\text { close }_{t-1} \mid \\
\mid \operatorname{low}_{t}-\text { close }_{t-1} \mid
\end{array}\right.
$$

The comparison of differences between two consecutive lows with the difference between their respective highs indicates the directional movement. The plus DM (+DM) is a situation when current high minus the prior high is greater than the previous low minus the current low (see eq. 2). The opposite relationship points at the minus DM (-DM). The -DM equals, therefore, current high minus the prior high and the -DM equals prior low minus the current low (see eq. 3). The Directional Movement is by assumption positive, therefore in the case when an indicator is a negative number then is set to zero. Formally:

$$
\begin{aligned}
& +D M_{t}=\max \left\{0 ; \text { high }_{t}-\text { high }_{t-1}\right\} \\
& -D M_{t}=\max \left\{0 ; \operatorname{low}_{t-1}-\operatorname{low}_{t}\right\}
\end{aligned}
$$

When both $-\mathrm{DM}$ and $+\mathrm{DM}$ equals zero, then its points at an inside day, when no directional movement is observed. In order to capture a real tendency in the trend change, it is necessary to introduce a smoothing parameter. In our work, we follow the Wilders' original assumptions, and we will average indicators over 14 days. In notation, we use 14 in a low index to signal the number of days over which the smoothing will be performed.

The initial value of a smoothed true range $\left(T R_{t_{0}}\right)$ is a simple sum of a TR over a number of days (see eq. 4 ). The same rule applies to the initial values of Directional Movement $\left(D M_{t_{0}}\right)$ (see eq. 6).

$$
T R_{14\left(t_{0}\right)}=\sum_{i=1}^{14} T R_{i}
$$

The values of a smoothed TR for the next periods are calculated as a sum of thirteen times the previous value of
TR and the value of a true range of a current period divided by fourteen (see eq. 5).

$$
T R_{14\left(t_{i}\right)}=T R_{14\left(t_{i-1}\right)}-\frac{T R_{14\left(t_{i-1}\right)}}{14}+T R_{t_{i}}
$$

This smoothing technique has the application to other smoothed indicators used in the paper and are calculated as in eq. 7-10:

$$
\begin{aligned}
& D M_{14\left(t_{0}\right)}=\sum_{i=1}^{14} D M_{i} \\
& +D M_{14\left(t_{1}\right)}=+D M_{14\left(t_{0}\right)}-\frac{+D M_{14\left(t_{0}\right)}}{14}+D M_{t_{1}} \\
& +D M_{14\left(t_{i}\right)}=+D M_{14\left(t_{i-1}\right)}-\frac{+D M_{14\left(t_{i-1}\right)}}{14}+D M_{t_{i}} \\
& -D M_{14\left(t_{1}\right)}=-D M_{14\left(t_{0}\right)}-\frac{-D M_{14\left(t_{0}\right)}}{14}+-D M_{t_{1}} \\
& -D M_{14\left(t_{i}\right)}=-D M_{14\left(t_{i-1}\right)}-\frac{-D M_{14\left(t_{i-1}\right)}}{14}+-D M_{t_{i}}
\end{aligned}
$$

The Directional Indicator (DI) is calculated as a quotient of smoothed plus or minus Directional Movement and smoothed True Range (see eq. 11-12), thus it reflects the percent of the true range that is up or down for the day. It is important to notice that on a specific day, only one from both states finds application +DI or -DI, as it is impossible to have directional movements in opposites directions on one day.

$$
\begin{aligned}
& +D I_{14(t)}=\frac{+D M_{14}(t)}{T R_{14}(t)} \cdot 100 \% \\
& -D I_{14(t)}=\frac{-D M_{14}(t)}{T R_{14}(t)} \cdot 100 \%
\end{aligned}
$$

True Directional Movement (TDM) is calculated as a difference between plus Directional indicator and minus Directional indicator (see eq. 13). It gives information of a part of the price movement, which is moving non directional.

$$
T D M_{t}=+D I_{14(t)}--D I_{14(t)}
$$

Directional Movement Index (DX) is a quotient of a True Directional Movement and a sum of a plus Directional Indicator and a minus Directional Indicator (see eq. 14).

$$
D X_{t}=\frac{T D M_{t}}{+D I_{14(t)}+-D I_{14(t)}} \cdot 100 \%
$$

After smoothing the Directional Movement Index over 14 days, we received an Average Directional Movement Index (ADX). The applied technic is analogous to the above already described (see eq.15 - 16).

$$
\begin{aligned}
& A D X_{14\left(t_{0}\right)}=\sum_{i=1}^{14} A D X_{i} \\
& A D X_{\left(t_{i}\right)}=\frac{13 \times A D X_{\left(t_{i-1}\right)}+D X_{t_{i}}}{14}
\end{aligned}
$$

ADX finds its application in different trading strategies. It is accepted that if ADX is above 25, then prices follow a strong trend. Plus and Minus Directional Indicators are used as a support lines for ADX. Both lines are an indicator of a direction of the directional movement and complement the ADX indicator, which reflects the strength of the directional movement, hence it is important to interpret both indicators, $\mathrm{ADX}$ and DI, together. If the directional movement is up, than + DI $>-$ DI. If the direction is down, than + DI $<-$ DI.

\section{Empirical Results}

In our analysis, we compared the distribution of strength of the directional movement across different exchanges (Bitstamp [Bitstp], Coinbase [CB], Kraken[Kr]) within the up and the downward price movement phase. The investigated sample covers the period from 01.01.2015 to 25.06.2019. The 
data was smoothed over 14 days, which is in line with Wilders' original assumptions described in his book.

The significant differences are visible between the upward trend and the downward trend phase, both in the entire analyzed period (see table 1) and in the phase of the strong directional movement (see table 2). In both situations, the upward trend is dominated by the downward trend. Both the length and number of periods of the downward trend differ significantly from the upward price movement. It should be remembered that negative information, concerning both cryptocurrencies and crypto markets, appear systematically, which in combination with the large variability of crypto-assets and situations, in which money deposited on stock exchanges are being stolen, causes a significant sense of uncertainty among investors and greater sensitivity to negative information, but also fluctuations in rates, than is the case with traditional assets.

Table 1

Basic Statistics for ADX in Up (1) and Down (2) Trend Across three Crypto Exchanges (Coinbase, Bitstamp, Kraken)

\begin{tabular}{|c|c|c|c|c|c|c|c|c|c|}
\hline Trend & Exchange & $\begin{array}{c}\text { ADX } \\
\text { Means }\end{array}$ & $\begin{array}{c}\text { ADX } \\
\mathbf{N}\end{array}$ & $\begin{array}{c}\text { ADX } \\
\text { Std.Dev. }\end{array}$ & $\begin{array}{c}\text { ADX } \\
\text { Minimum }\end{array}$ & $\begin{array}{c}\text { ADX } \\
\text { Maximum }\end{array}$ & $\begin{array}{l}\text { ADX } \\
\text { Q25 }\end{array}$ & $\begin{array}{c}\text { ADX } \\
\text { Median }\end{array}$ & $\begin{array}{c}\text { ADX } \\
\text { Q75 }\end{array}$ \\
\hline \multirow{3}{*}{1} & Coinbase & $11,0 \%$ & 529 & $4,3 \%$ & $4,3 \%$ & $28,9 \%$ & $8,0 \%$ & $10,1 \%$ & $12,8 \%$ \\
\hline & Bitstamp & $11,0 \%$ & 590 & $5,8 \%$ & $4,1 \%$ & $56,2 \%$ & $7,6 \%$ & $9,6 \%$ & $12,6 \%$ \\
\hline & Kraken & $10,5 \%$ & 625 & $3,9 \%$ & $3,2 \%$ & $22,3 \%$ & $7,4 \%$ & $9,5 \%$ & $13,0 \%$ \\
\hline \multirow{3}{*}{2} & Coinbase & $14,7 \%$ & 1070 & $9,0 \%$ & $3,8 \%$ & $48,8 \%$ & $7,6 \%$ & $12,3 \%$ & $18,6 \%$ \\
\hline & Bitstamp & $12,5 \%$ & 1009 & $7,0 \%$ & $3,8 \%$ & $34,0 \%$ & $7,1 \%$ & $10,3 \%$ & $16,4 \%$ \\
\hline & Kraken & $12,5 \%$ & 974 & $6,0 \%$ & $2,9 \%$ & $35,3 \%$ & $7,9 \%$ & $11,0 \%$ & $15,9 \%$ \\
\hline \multicolumn{2}{|r|}{ All Groups } & $12,4 \%$ & 4797 & $6,8 \%$ & $2,9 \%$ & $56,2 \%$ & $7,6 \%$ & $10,5 \%$ & $15,4 \%$ \\
\hline
\end{tabular}

Table 2

Basic Statistics for ADX in Up (1) and Down (2) Trend Across three Crypto Exchanges (Coinbase, Bitstamp, Kraken) Within the Strong Directional Movement (ADX>25)

\begin{tabular}{clccccccccc}
\hline \multirow{2}{*}{ Trend } & Exchange & $\begin{array}{c}\text { ADX } \\
\text { Means }\end{array}$ & $\begin{array}{c}\text { ADX } \\
\text { N }\end{array}$ & $\begin{array}{c}\text { ADX } \\
\text { Std.Dev. }\end{array}$ & $\begin{array}{c}\text { ADX } \\
\text { Variance }\end{array}$ & $\begin{array}{c}\text { ADX } \\
\text { Minimum }\end{array}$ & $\begin{array}{c}\text { ADX } \\
\text { Maximum }\end{array}$ & $\begin{array}{c}\text { ADX } \\
\text { Q25 }\end{array}$ & $\begin{array}{c}\text { ADX } \\
\text { Median }\end{array}$ & $\begin{array}{c}\text { ADX } \\
\text { Q75 }\end{array}$ \\
\hline \multirow{2}{*}{1} & Coinbase & $26,9 \%$ & 7 & $1,2 \%$ & $0,0 \%$ & $25,1 \%$ & $28,9 \%$ & $25,8 \%$ & $27,0 \%$ & $27,7 \%$ \\
& Bitstamp & $38,1 \%$ & 14 & $9,7 \%$ & $0,9 \%$ & $25,5 \%$ & $56,2 \%$ & $30,7 \%$ & $36,2 \%$ & $45,5 \%$ \\
& Kraken & & 0 & & & & & & & \\
\hline \multirow{2}{*}{2} & Coinbase & $33,5 \%$ & 133 & $6,4 \%$ & $0,4 \%$ & $25,0 \%$ & $48,8 \%$ & $28,9 \%$ & $32,3 \%$ & $36,0 \%$ \\
& Bitstamp & $28,8 \%$ & 84 & $2,5 \%$ & $0,1 \%$ & $25,0 \%$ & $34,0 \%$ & $26,9 \%$ & $28,2 \%$ & $30,6 \%$ \\
& Kraken & $29,6 \%$ & 39 & $3,3 \%$ & $0,1 \%$ & $25,2 \%$ & $35,3 \%$ & $27,0 \%$ & $28,6 \%$ & $32,7 \%$ \\
\hline
\end{tabular}

The ADX distribution (see Figure 1) accompanied with the results of the Kolmogorov Smirnov Normality test (see Table 3), which assumes Normality under H0, point at the

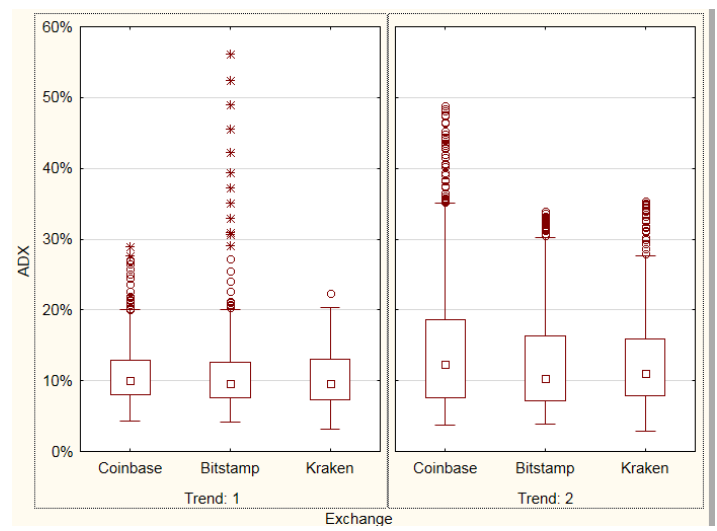

Figure 1. ADX Distribution in Upward (trend 1) and Downward (trend 2) Price Movement statistically significant deviation from the normal distribution ( $p>0.05)$, therefore in further research the nonparametric test will be applied.

Table 3

\begin{tabular}{|c|c|c|c|c|c|c|}
\hline & Full & $\mathbf{p}$ & Up & $\mathbf{p}$ & Down & $\mathbf{p}$ \\
\hline oinbase & 0,134 & $<0.010$ & 0,102 & $<0.010$ & 0,127 & $<0.010$ \\
\hline Bitstamp & 0,136 & $<0.010$ & 0,147 & $<0.010$ & 0,132 & $<0.010$ \\
\hline kcoin & 0,235 & $<0.010$ & 0,274 & $<0.010$ & 0,172 & $<0.010$ \\
\hline Kraken & 0,114 & $<0.010$ & 0,110 & $<0.010$ & 0,128 & $<0.010$ \\
\hline
\end{tabular}

We perform distribution analysis of ADX covering three potential scenarios. In the first case, using the Wilcoxon test, we check whether the rank distribution does not differ from each other in terms of the central measure, but may vary in terms of displacement. Assumption of the comparability of the value of the central measure but with varying degrees of data spread around the mean value will be tested using the Ansari-Bradley test. The third shift occurs when both the measures of central tendencies and the scale parameter differ, which will be checked by the Conover 
test. Compilation of such tests allows formulating more general conclusions resulting from possible similarities of cryptocurrency markets in terms of the strength of the directional movement. The technical details concerning above mentioned test are to be found in Sheskin (2007), Daniel (1990), Conover (1999), Hollander \& Wolfe (1999).

The results of an application of a Wilcoxon test, AnsariBradley test, and Conover test on ADX in terms of location, shift, and dispersion respectively are summarized in Table 4. We tested the behavior of the index in its various phases. The two most natural are the upward and downward trend. Additionally, we examined whether the index behavior changes in the period with a strong trend, a situation where the ADX level exceeds 25.

Table 4

Comparison of Distribution Test Results for Cryptocurrency Markets: Bitstamp, Coinbase, Kraken

\begin{tabular}{cl|ccc}
\hline \multicolumn{2}{c|}{ p-Value } & $\begin{array}{c}\text { Kruskal } \\
\text { Wallis }\end{array}$ & $\begin{array}{c}\text { Ansari } \\
\text { Bradley }\end{array}$ & Conover \\
\cline { 2 - 5 } & UP & $\mathbf{0 . 1 5 6 8}$ & $\mathbf{0 . 1 1 8 4}$ & $\mathbf{0 . 4 8 2 7}$ \\
& Down & $<.0001$ & $<.0001$ & $<.0001$ \\
\hline ADX $>25$ & UP & 0.0022 & $\mathbf{0 . 5 1 9 3}$ & 0.0036 \\
& Down & $<.0001$ & 0.0069 & $<.0001$ \\
\hline
\end{tabular}

There are visible differences in the results of the analyzed tests in the bullish market compared to the bearish market phase. They are also evident when comparing the period of strong directional movement phase within the total sample. The results show that in the upward trend, for the full sample, the $p$-Values were unambiguously above the significance level, hence there is no basis for rejection of the Null Hypothesis. Therefore, it can be assumed that the distributions of the directional index do not differ

significantly among exchanges in the bearish market. In the strong trend phase, when ADX > 25, only in case of the Ansari Bradley test, the Null Hypothesis was not rejected. Therefor it may be assumed that, there are no significant differences in the distribution of ADX in value of the central measure but with varying degrees of data spread around the mean. The obtained results, however, do not constitute a confirmation of the assumption about the similarity of distributions, due to a small sample, which occurred for the strong directional movement phase. Considering the downward trend, for both samples, for all tests we performed, the p-values were significantly lower than the assumed level of significance, which points at the necessity of the rejection of the Null Hypothesis, assuming the distribution function are different in terms of central measure, shift in mean and dispersion in both analyzed periods. Hence the choose of the exchange by the investors during the bearish phase can cause differences in achieved returns, which in turn can affect the choice of investment strategy.

In our analysis, we performed the additional analysis, to check whether the results hold in the pair comparisons (see Table 5). The received results for the upward trend are comparable with the above presented results. The only difference is visible while comparing Coinbase and Kraken. In this case the Null Hypothesis of the Ansari Bradley should be rejected, which points ate the differences in the distribution of the trend strength in terms of the central measure. The comparison in pairs allows for applying the Hodges Lehmann test, which helps to determine the median unbiased estimate value of the shift and the associated confidence interval. The estimated shifts for the full sample in the upward trend are very low, what in the context of other tests results confirms the resemblance of the ADX distributions among all three exchanges.

Table 5

Comparison of Distribution of the Test Results in the Upward Trend, in the Bilateral Comparison

\begin{tabular}{l|ccccc}
\hline & $\begin{array}{c}\text { Kruskal } \\
\text { Wallis }\end{array}$ & $\begin{array}{c}\text { Ansari } \\
\text { Bradley }\end{array}$ & Conover & $\begin{array}{c}\text { Hodges } \\
\text { Lehmann }\end{array}$ & $\begin{array}{c}\text { 95\% Confidence } \\
\text { Limits* }\end{array}$ \\
\hline CB vs. Bitstp & 0.1386 & 0.2384 & 0.3395 & 0.0032 & -0.0010 \\
CB vs. Kr & 0.0664 & $\mathbf{0 . 0 3 3 6}$ & 0.1962 & 0.0040 & 0.0076 \\
Bitstp vs. Kr & 0.7005 & 0.2317 & 0.7199 & 0.0008 & -0.0003 \\
\hline
\end{tabular}

Notation: $C B$ - Coinbase, Bitstp - Bitstamp, $\mathrm{Kr}$ - Kraken

* CI and Asymptotic Standard Error for Hodges Lehmann Test

There are some differences in the downward phase while comparing crypto markets individually, i.e. Coinbase with Bitstamp and Bitstamp with Kraken, (see Table 6). In the first case, the Ansari Bradley test p-values are higher than the level of significance, which points at no significant differences in ADX distribution, in the context of central measure. The $\mathrm{p}$-value close to the significance level was obtained by Kruskal Wallis test in the comparison of the Bitstamp and Kraken. In this case, it can be concluded that there may be similarities in rank distribution in terms of the central measure, but may vary in terms of displacement, which according to the Hodges Lehmann test equals 0.0046.

Comparison of Distribution of the Test Results in the Downward Trend, in the Bilateral Comparison

Table 6

\begin{tabular}{l|cccccc}
\hline & $\begin{array}{c}\text { Kruskal } \\
\text { Wallis }\end{array}$ & $\begin{array}{c}\text { Ansari } \\
\text { Bradley }\end{array}$ & Conover & $\begin{array}{c}\text { Hodges } \\
\text { Lehmann }\end{array}$ & $\begin{array}{c}\text { 95\% Confidence } \\
\text { Limits* }\end{array}$ & $\begin{array}{c}\text { Asymptotic } \\
\text { Standard Error* }\end{array}$ \\
\hline CB vs. Bitstp & $<0.0001$ & $\mathbf{0 . 2 7 4 0}$ & $<0.0001$ & -0.0126 & -0.0176 & -0.0077 \\
CB vs. Kr & 0.0005 & $<0.0001$ & $<0.0001$ & -0.0088 & -0.0140 & -0.0038 \\
Bitstp vs. Kr & $\mathbf{0 . 0 4 5 4}$ & $<0.0001$ & $<0.0001$ & $\mathbf{0 . 0 0 4 6}$ & 0.0001 & 0.0090 \\
\hline
\end{tabular}


The bilateral analysis of the strong downward trend (see Table 7) is also partially inconsistent with the results presented above for the full sample (see Table 4). Generally test confirmed dissimilarities in the ADX distribution among exchanges except for the comparison of the Coinbase and Kraken, in which case the Ansari Bradley was not able to reject the Null Hypothesis. Thus it can be assumed that the ADX for these two exchanges comes from similar distributions. While comparing Bitstamp and Kraken, the high p-value of the Kruskall Wallis test points at the similarities in the rank distribution in terms of the central measure, but it varys in terms of displacement, which according to the Hodges Lehmann test equals 0.0045.

Table 7

Comparison of Distribution Test Results for a Strong Downward in the Bilateral Comparison: Coinbase-Bitstamp, CoinbaseKraken, Bitstamp-Kraken in the Downward Trend

\begin{tabular}{l|cccccc}
\hline & $\begin{array}{c}\text { Kruskal } \\
\text { Wallis }\end{array}$ & $\begin{array}{c}\text { Ansari } \\
\text { Bradley }\end{array}$ & Conover & $\begin{array}{c}\text { Hodges } \\
\text { Lehmann }\end{array}$ & $\begin{array}{c}\text { 95\% Confidence } \\
\text { Limits* }\end{array}$ & $\begin{array}{c}\text { Asymptotic } \\
\text { Standard Error* }\end{array}$ \\
\hline CB vs. Bitstp & $<0.0001$ & 0.0117 & $<0.0001$ & -0.0359 & -0.0496 & -0.0238 \\
CB vs. Kr & 0.0009 & $\mathbf{0 . 4 3 1 7}$ & 0.0004 & -0.0308 & -0.0496 & -0.0117 \\
Bitstp vs. Kr & $\mathbf{0 . 4 1 8 0}$ & 0.0179 & 0.0026 & $\mathbf{0 . 0 0 4 5}$ & -0.0057 & -0.0165 \\
\hline
\end{tabular}

\section{Conclusions}

Information on the distribution of the directional movement index, which indicates the strength of the directional movement on analyzed exchanges is vital for potential investors, who are wishing to shape their investment strategies in cryptocurrencies consciously. According to the Directional Movement System, when $+\mathrm{DI}_{14}$ crosses $-\mathrm{DI}_{14}$, than the long position should be taken. When in contrary $-\mathrm{DI}_{14}$ crosses $+\mathrm{DI}_{14}$ than the short position should be an advantage. Wilders investing strategy is profitable when ADX reaches values above 25 . The results show that the aware investors should carefully, in line with the planned investment strategy, choose the cryptocurrency market. While, theoretically, the choice of a cryptocurrency exchange in an upward trend will perform no significant difference for an investor and its strategy, however, the choice of a cryptocurrency exchange in a downward trend may have a considerable impact on the rates of return. There are statistically significant differences in the strength level of ADX among exchanges. The highest ADX values are reported by Coinbase ca. 49\%. The other two exchanges generate values around $35 \%$. This indicates that on the Coinbase the down trend is much stronger than on the other two markets. Also, the number of days, where the downward trend was observed varies among the exchanges. In a phase, when the strong trend was observed, only the Coinbase had the longest down run (in total over 130 days). These results show that buying the dips strategy should be the most profitable on Coinbase market. There is certainly no single, correct explanation for the causes of this phenomenon. It can be presumed that stock exchanges with shorter downturns have a more stable position among investors, and thus return to balance faster after negative information reaching the market that negatively affects bitcoin quotations or has less liquidity and even insignificant transaction may cause a faster price increase. Our results also show that the cryptocurrency market is far to meet the assumption of the effective market hypothesis and is still susceptible to arbitrage.

\section{References}

Alexander, S. S. (1961a). Price Movements in Speculative Markets: Trends or Random Walks. Industrial Management Review, 2, 7-26.

Alexander, S. S. (1961b). Price Movements in Speculative Markets: Trends or Random Walks No 2. Cootner's.

Alshamsi, A., \& Andras, P. (2019). User perception of Bitcoin usability and security across novice users. International Journal of Human-Computer Studies, 126, 94-110. https://doi.org/10.1016/j.ijhcs.2019.02.004

Badev, A., \& Chen, M. (2014). Bitcoin: Technical Background and Data Analysis. Finance and Economics Discussion Serie, Divisions of Research \& Statistics and Monetary Affairs, Federal Reserve Board, Washington, D.C. https://doi.org/10.17016/feds.2014.104

Bariviera, A. (2017). The Inefficiency of Bitcoin Revisited: A Dynamic Approach. Economics Letters, 161, 1-4. https://doi.org/10.1016/j.econlet.2017.09.013

Biryukov, A., \& Tikhomirov, S. (2019). Security and privacy of mobile wallet users in Bitcoin, Dash, Monero, and Zcash. Pervasive and Mobile Computing, 59. https://doi.org/10.1016/j.pmcj.2019.101030

Bouoiyour, J., \& Selmi, R. (2016). Bitcoin: A beginning of a new phase? Economics Bulletin, 36(3), 1430-1440.

Brandvolt, M., Molnar, P., Vagstad, K., \& Valstad, O. (2015). Price discovery on Bitcoin exchanges. Journal of International Financial Markets, Institutions and Money, 36, 18-35. https://doi.org/10.1016/j.intfin.2015.02.010

Brauneis, A., \& Mestel, R. (2018). Price discovery of cryptocurrencies: Bitcoin and beyond. Economics Letters, 165, 5861. https://doi.org/10.1016/j.econlet.2018.02.001 
Bryans, D. (2014). Bitcoin and Money Laundering: Mining for an Effective Solution. Indiana Law Journal, 89(1), 441472.

Campbell-Verduyn, M. (2018). Bitcoin, crypto-coins, and global anti-money laundering governance. Crime, Law and Social Change, 69(2), 283-305. https://doi.org/10.1007/s10611-017-9756-5

Cheah, E., \& Fry, J. (2015). Speculative bubbles in Bitcoin markets? An empirical investigation into the fundamental value of Bitcoin. Economics Letters, 130, 32-36. https://doi.org/10.1016/j.econlet.2015.02.029

Conover, W. (1999). Practical nonparametric statistics. John Wiley \& Sons, Inc.

Corbet, S., Lucey, B., \& Yarovaya, L. (2018). Date stamping the Bitcoin and Ethereum bubbles. Finance Research Letters, 26, 81-88. https://doi.org/10.1016/j.frl.2017.12.006

Czaplinski, T., \& Nazmutdinova, E. (2019). Using FIAT currencies to arbitrage on cryptocurrency exchange. Journal of International Studies, 15(1), 184-192. https://doi.org/10.14254/2071-8330.2019/12-1/12

Dahel, R., \& Laabas, B. (1999). The Behavior of Stock Prices in the GCC Markets. Journal of Development \& Economic Policies, 1, 89-105.

Daniel, W. (1990). Applied nonparametric statistics. Duxbury Thomson Learning.

Demir, E., Gozgor, G., Lau, C., \& Vigne, S. (2018). Does economic policy uncertainty predict the Bitcoin returns? An empirical investigation. Finance Research Letters, 26, 145-149. https://doi.org/10.1016/j.frl.2018.01.005

Detzel, A. L., Liu, H., Strauss, J., Zhou, G., \& Zhu, Y. (2018). Bitcoin: Learning, predictability and profitability via technical analysis. Retrieved from https://ssrn.com/abstract=3115846. https://doi.org/10.2139/ssrn.3115846

Dhar, S., \& Chhaochharia, S. (2008). Market Reaction Around the Stock Splits and Bonus Issues: Some Indian Evidence. Working Paper Series. https://doi.org/10.2139/ssrn.1087200

Dwyer, G. (2015). The economics of Bitcoin and similar private digital currencies. Journal of Financial Stability, 17, 8191. https://doi.org/10.1016/j.jfs.2014.11.006

Fama, E. F. (1991). Efficient Capital Markets II. Journal of Finance, XLVI, 1575-1617. https://doi.org/10.1111/j.15406261.1991.tb04636.x

Fama, E. F. (1970). Efficient Capital Markets: A Review of Theory and Empirical Work. The Journal of Finance, 25(2), 383-417. https://doi.org/10.2307/2325486

Fama, E., \& Blume, M. (1966). Filter Rules and Stock Market Trading Profits. Journal of Buisiness, 39, $226-241$. https://doi.org/10.1086/294849

Feng, W., Wang, Y., \& Zhang, Z. (2018). Informed trading in the Bitcoin market. Finance Research Letters, 26, 63-70. https://doi.org/10.1016/j.frl.2017.11.009

FSB (Financial Stability Board). (2018). Crypto-asset markets. Potential channels for future financial stability implications. Retrieved from https://www.fsb.org/wp-content/uploads/P101018.pdf

Gandal, N., Hamrick, J. T., Moore, T. \& Oberman, T. (2018). Price manipulation in the Bitcoin ecosystem. Journal of Monetary Economics, 95, 86-96. https://doi.org/10.1016/j.jmoneco.2017.12.004

Garrat, R., \& Wallace, N. (2018). Bitcoin 1, bitcoin 2, ....: an experiment in privately issued outside monies. Economic Inquiry, 56(3), 1887-1897. https://doi.org/10.1111/ecin.12569

Granger, C. (1975). A Survey of Empirical Studies on Capital Markets. (E. E. Gruber, Ed.) North-Holland, Amsterdam: International Capital Markets .

Hadi, M. M. (2006). Review of Capital Market Efficiency: Some Evidence from Jordanian Market. International Research Journal of Finance and Economics, 13-26.

Hamid, K., Suleman, M., Shah, S., \& Akash, R. (2010). Testing the weak form of efficient market hypothesis: Empirical evidence from Asia-Pacific markets. International Research Journal of Finance and Economics, 58, 121-133.

Haubo Dyhrberg, A. (2016a). Hedging capabilities of bitcoin. Is it the virtual gold? Finance Research Letters, 16, $139-144$. https://doi.org/10.1016/j.frl.2015.10.025

Haubo Dyhrberg, A. (2016b). Bitcoin, gold and the dollar - A GARCH volatility analysis. Finance Research Letters, 16, 85-92. https://doi.org/10.1016/j.frl.2015.10.008

Hawawini, G. (1984). European Equity Markets: Price Behavior and Efficiency. Salomon Brothers Center for the Study of Financial Institutions, Graduate School of Business Administration, New York University, Monograph 4/5.

Hollander, M., \& Wolfe, D. (1999). Nonparametric Statistical Methods. Wiley-Interscience. 
Huang, J. Z., Huang, W., \& Ni, L. (2019). Predicting bitcoin returns using high-dimensional technical indicators. The Journal of Finance and Data Science, 5(3), 140-155. https://doi.org/10.1016/j.jfds.2018.10.001

Hudson, R., \& Urquhart, A. (2019). Technical trading and cryptocurrencies. Annals of Operations Research, 1-30. https://doi.org/10.1007/s10479-019-03357-1

Jagwani, B. (2015). Bitcoins demystified. International Journal of Marketing. Financial Services \& Management Research, $4(4), 29-35$.

Jensen, M. C. (1978). Some Anomalous Evidence Regarding Market Efficiency. Journal of Financial Economics, 6(2/3), 95-101. https://doi.org/10.1016/0304-405X(78)90025-9

Joseph, N. R., Kumar, N., Dr. Lokesh, \& Kumar, K. A. (2017). Earnings Information and Stock Market Efficiency. American Scientific Research Journal for Engineering, Technology, and Sciences, 31(1), 92-100.

Kiss, G. D., Savai, M., \& Udvari, B. (2017). Missing Data Bias on a Selective Hedging Strategy. Journal of Competitiveness, 9(1), 15-19. https://doi.org/10.7441/joc.2017.01.01

Koutmos, D. (2018). Bitcoin returns and transaction activity. Economics Letters, 167, 81-85. https://doi.org/10.1016/ j.econlet.2018.03.021

Liu, J., Kauffman, R., \& Ma, D. (2015). Competition, cooperation, and regulation: Understanding the evolution of the mobile payments technology ecosystem. Electronic Commerce Research and Applications, 14(5), 372-391. https://doi.org/10.1016/j.elerap.2015.03.003

Lo, A. W. (1997). Market Efficiency: Stock Market Behavior in Theory and Practice. Chethenham, UK: An Elgar Reference Collection.

Luther, W. J., \& Olson, J. (2015). Bitcoin is Memory. Journal of Prices \& Markets, 3(3), 22-33.

Mackey, A. M., \& Bacon, F. W. (2017). Signaling with Stock Issues and Repurchases: a Test of Semi-Strong Form Market Efficiency. Journal of Business and Behavioral Sciences, 29(1), 34-44.

Mandjee, T. (2015). Bitcoin, Its Legal Classification and Its Regulatory Framework. Journal of Business \& Securities Law, $15(2)$.

Muharam, H., Wisnu, M., Arfinto, E. D., \& Najmudin. (2019). Volatility spillovers under difference in the degree of market integration: Evidence from the selected Asian and Eastern European stock markets. Journal of International Studies, 12(1), 134-150. https://doi.org/10.14254/2071-8330.2019/12-1/9

Nadarajah, S., \& Chu, J. (2017). On the inefficiency of Bitcoin. Economics Letters, 150, 6-9. https://doi.org/10.1016/ j.econlet.2016.10.033

Naseer, M., \& Tariq, Y. (2015). The Efficient Market Hypothesis: A Critical Review of the Literature. The IUP Journal of Financial Risk Management, XII(4), 48-63.

Pieters, G., \& Vivanco, S. (2017). Financial regulations and price inconsistencies across Bitcoin markets. Information Economics and Policy, 39, 1-14. https://doi.org/10.1016/j.infoecopol.2017.02.002

Plassaras, N. A. (2013). Regulating Digital Currencies: Bringing Bitcoin within the Reach of IMF. Chicago Journal of International Law, 14, 377-408.

Plastun, A., Kozmenko, S., Plastun, V., \& Filatova, H. (2019). Market anomalies and data persistence: The case of the dayof-the-week effect. Journal of International Studies, 12(3), 122-130. https://doi.org/10.14254/2071-8330.2019/12$3 / 10$

Rogojanu, A., \& Badea, L. (2015). The issue of "true" money in front of the BitCoin's offensive. Theoretical and Applied Economics, XXII (2(603)), 77-90.

Salim, L., Stelios, B., \& Salvi, A. (2018). Long-range memory, distributional variation and randomness of bitcoin volatility. Chaos, Solitons and Fractals, 107, 43-48. https://doi.org/10.1016/j.chaos.2017.12.018

Sheskin, D. (2007). Handbook of parametric and nonpa $\neg$ rametric statistical procedures. Chap-man \& Hall /CRC.

Shiller, R. (1981). The use of volatility measures in assessing market efficiency. Journal of Finance, 36, $291-304$. https://doi.org/10.1111/j.1540-6261.1981.tb00441.x

Szetela, B., Mentel, G., \& Gedek, S. (2016). Dependency analysis between bitcoin and selected global currencies. Dynamic Econometric Models, 16, 133-144. https://doi.org/10.12775/DEM.2016.009

Urquhart, A. (2016). The inefficiency of Bitcoin. Economics Letters, 148, 80-82. https://doi.org/10.1016/j. econlet.2016.09.019 
Urquhart, A. (2017). Price clustering in Bitcoin. Economics Letters, 159, 145-148. https://doi.org/10.1016/ j.econlet.2017.07.035

Wilder Jr., J. (1978). New Concepts in Technical Trading Systems. Greensboro, NC: Hunter Publishing Company. Trend Research.

Worthington, A., \& Higgs, H. (2004). Random walks and market efficiency in European equity markets. Global Journal of Finance and Economics, 1, 59-78.

Ziegeldorf, J. H., Matzutt, R., Henze, M., Grossmann, F., \& Wehrle, K. (2018). Secure and anonymous decentralized Bitcoin mixing. Future Generation Computer Systems, 80, 448-466. https://doi.org/10.1016/j.future.2016.05.018

Zbikowski, K. (2016). Application of Machine Learning Algorithms for Bitcoin Automated Trading. In D. RyZko, P. Gawrysiak, M. Kryszkiewicz, \& H. Rybinski, Machine Intelligence and Big Data in Industry (Studies in Big Data, vol 19, pp. 161-168). Springer. https://doi.org/10.1007/978-3-319-30315-4_14

The article has been reviewed.

Received in January 2020; accepted in April 2020. 